\title{
Optimum integration of a large size collector to a solar thermal power plant
}

\author{
M. Yaghoubi ${ }^{1, *}$, S. Zarrini ${ }^{1}$, S. Mirhadi ${ }^{2}$ \\ ${ }^{1}$ Engineering School, Shiraz University, Shiraz, Iran \\ ${ }^{2}$ Renewable Energy Organization of Iran, Tehran, Iran \\ * Corresponding author. Tel: +98 7116133028,Fax: +98 7112301672, E-mail: yaghoubi@shirazu.ac.ir
}

\begin{abstract}
In this paper the problem of increasing the capacity of an already constructed solar thermal power plant has been studied through the concept of lost available work. The required increased capacity has been proposed to be achieved by means of a new large size collector and an auxiliary boiler. Two different schemes along with an extra scheme for night operation of the power plant have been considered in the present work. For each scheme, three different operating conditions have been assumed, resulting in a total of nine operating options. For these options, results of analysis based on the second law of thermodynamics have been presented. These results might then be used to choose the optimum solar hybrid power plant configuration.
\end{abstract}

Keywords: Renewable energy, Solar thermal power plant, Parabolic trough, Exergy, Entropy generation

\section{Nomenclature}

$\dot{W}$ work interaction $k W$

$\dot{S}_{\text {gen }}$ entropy generation rate .$k W \cdot K^{-1}$

$\dot{Q}$ heat interaction $k W$

$\dot{m}$ mass flow rate

$P$ pressure. bara

$T$ absolute temperature ................................

$T_{0} \quad$ dead state temperature .............................

$C_{p}$ constant pressure specific heat ... $\mathrm{kJ} . \mathrm{kg}^{-1} \cdot \mathrm{K}^{-1}$

$\mathrm{s} \quad$ specific entropy ....................... $\mathrm{kJ} \cdot \mathrm{kg}^{-1} \cdot \mathrm{K}^{-1}$

$h \quad$ specific enthalpy............................... $\mathrm{kJ} \mathrm{kg}^{-1}$

$v \quad$ specific volume ................................ $\mathrm{m}^{3} . \mathrm{kg}^{-1}$

\section{Introduction}

\subsection{Problem description}

Renewable energies play the key role in sustainable development and are the most promising remedy to the problem of air pollution worldwide. Among various sources of renewable energy, the usage of solar thermal energy in generating electricity can be regarded as the most reliable and developed one in the path of commercialization [1].

In Shiraz, Iran, the first solar thermal power plant (STPP) has been designed and constructed for $250 \mathrm{~kW}$ power generation [2]. For the first phase of development, this plant has been constructed and tested only to produce high pressure and high temperature steam (21 bar, and $250{ }^{\circ} \mathrm{C}$ ). This steam is then fed into the steam turbine of a conventional Rankine cycle. Based on the new feasibility study, it has been decided to increase the nominal capacity of this plant to $500 \mathrm{~kW}$ by adding a new large size (100 meters long) parabolic trough collector and employing an auxiliary boiler to provide the deficiency of steam as well as running the system during night periods (or day periods in which the solar radiation is insufficient).

Various schemes are possible to integrate the new collector to the field of available collectors. In this paper, two different cases (A, B) along with a night case are considered to be suitable for the new system. Assuming three different operating conditions (by setting the turbine outlet pressure) for each case, a total of nine configurations have been analyzed. The three outlet pressures considered are 10,25 and $100 \mathrm{kPa}$.

In the present article, these options are studied based on the first and second laws of thermodynamics. Each configuration has some advantages and disadvantages regarding 
overall thermal performance, installation and operating costs. To assess the overall performance of various configurations in a comparative manner, exergy method has been applied to the corresponding cycles (as a representative of the second law analysis). Exergy and exergoeconomic methods have received considerable attention during the past decade in the analysis and optimization of power plant cycles to achieve higher efficiencies and to reduce the operating cost of the corresponding power plants $[3,5]$.

For each case of the aforementioned cycles, results of exergy analysis are presented and exergetic losses due to various components (e.g. turbine, boiler, condenser etc) have been calculated. Finally the system with the best exergy efficiency to combine the new collector and increase the power rate of the plant is suggested for construction and operation.

\subsection{Current Configuration}

Shiraz solar thermal power plant consists of two separate cycles namely the oil cycle and the steam cycle. The oil cycle absorbs the solar radiation through collector field and transmits the harvested thermal energy to the steam cycle which is a classic Rankine cycle. The energy transfer between the two cycles takes place at three heat exchangers in series (E-201, E-202 and E-203). The collector field is composed of 8 parallel loops, each consisting of 6 collectors in series. The current configuration is able to produce $0.671 \mathrm{~kg} / \mathrm{s}$ of steam at $21 \mathrm{bar}$ and $250{ }^{\circ} \mathrm{C}$. This steam will be termed "field generated steam" as opposed to "boiler generated steam" which is the steam that is expected to be generated by the auxiliary boiler. A schematic of the plant is shown in Fig 1.

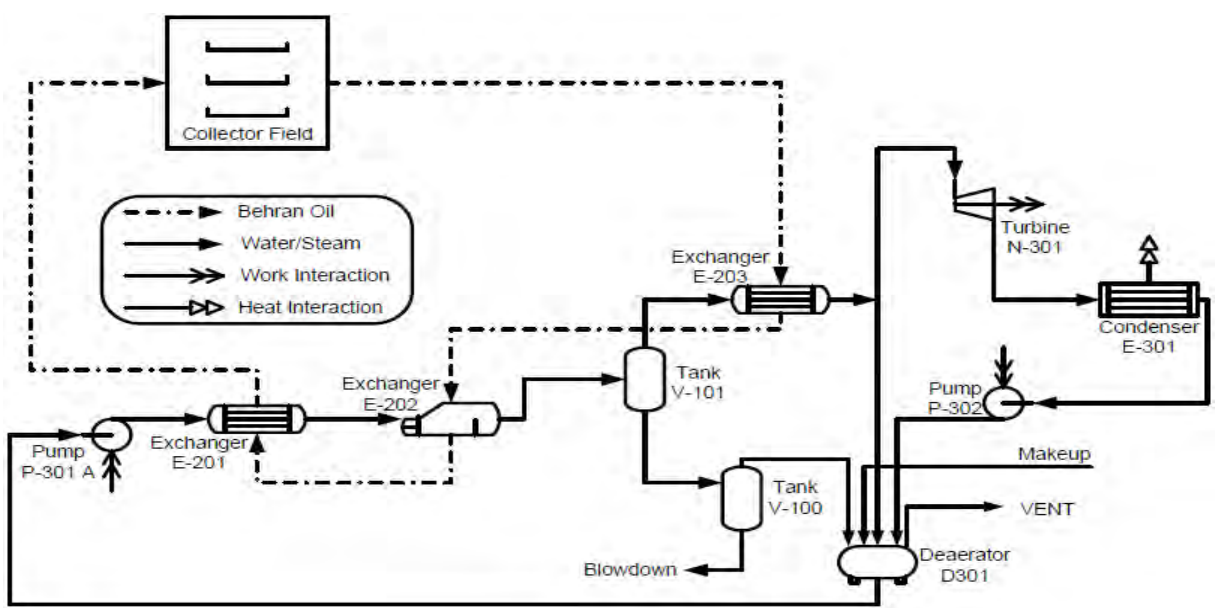

Fig. 1. Schematic of the current solar power plant.

\subsection{Integration of the new collector}

The new collector has been designed to bring Therminol VP-1 from $294^{\circ} \mathrm{C}$ to $313^{\circ} \mathrm{C}$, supplying $200 \mathrm{~kW}$ of energy to the system. This energy can be introduced into the current configuration in a variety of ways. Two different approaches have been considered in the present work namely case A and case B. In case A the boiler provides steam at $21 \mathrm{bar} 250^{\circ} \mathrm{C}$. This steam is then mixed with the field generated steam and the mixture is then becomes more superheated (to $294^{\circ} \mathrm{C}$ ) using available extra energy from the new collector in an extra heat exchanger (E-204). However, in case B, the boiler produces steam at 21 bar $294^{\circ} \mathrm{C}$ and in exchanger E-204, only the field generated steam becomes more superheated. The remaining energy from the new collector is then used to make the outlet oil from the field warmer, thus, increasing the amount of field generated steam. Therefore another extra exchanger is needed 
in case B to bring the VP-1 oil from the new collector and the Behran oil from the existing farm into thermal contact. Simplified depictions of cases A \& B are shown in Fig 2 and Fig 3.

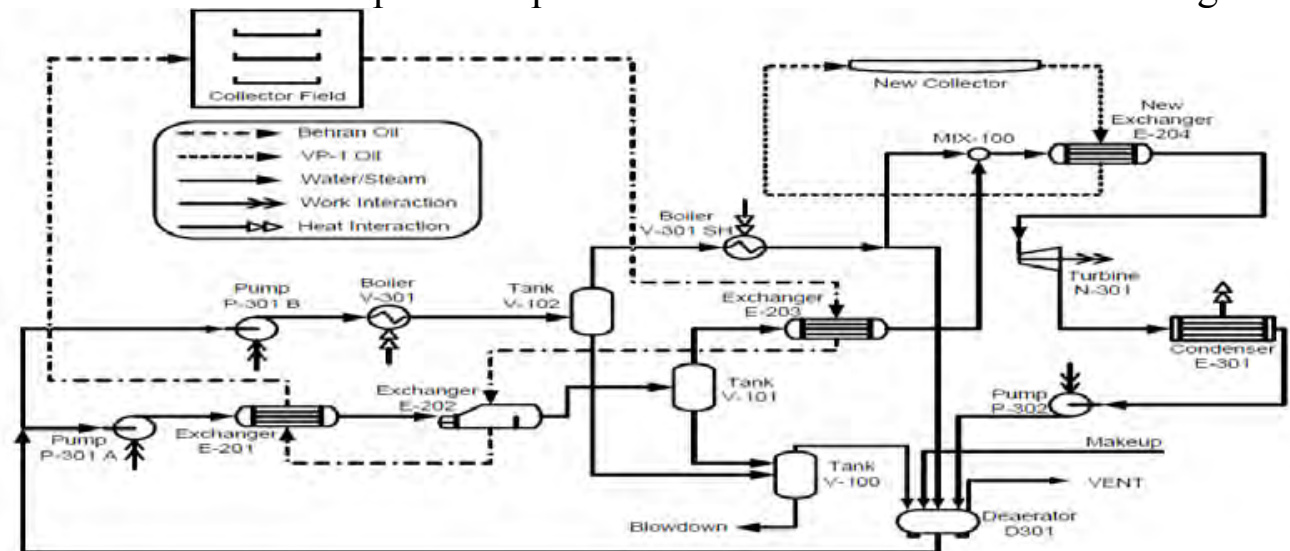

Fig. 2. Schematic of the proposed case A.

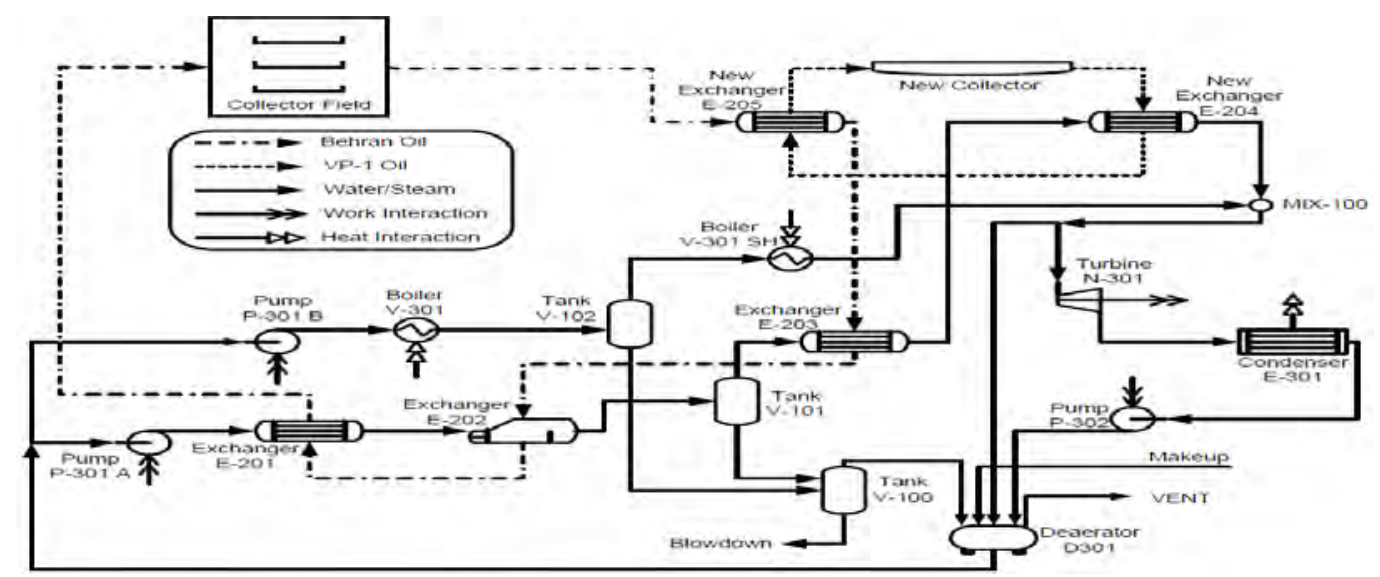

Fig. 3. Schematic of the proposed case B.

\section{Methodology}

As shortly explained in the preceding section, the problem at hand is a sort of semi-fixed system in which very few parameters are allowed to be altered. This is a direct consequence of the fact that we are dealing with a designed and constructed system and our attempt is to integrate a device into such a system which was not considered before. Thus we're not dealing with an ordinary optimization process in which particular parameters are allowed to vary in order to find the optimum set of parameters. Rather we are investigating the optimum case among a predefined set of choices. In other words, instead of optimizing the cycle, various predefined cases are compared based on the second law and the best can be chosen. The assessment of available options is done based on the destructed exergy associated with various components in each option. The destructed exergy (lost available work) is closely related to the rate of entropy generation through the following equation [4]:

$\dot{W}_{\text {lost }}=T_{0} \dot{S}_{\text {gen }}$

where $\mathrm{T}_{0}$ is the lowest temperature available for the system to reach theoretically (dead state). In this work the dead state has been assumed to be at $25^{\circ} \mathrm{C}$ and atmospheric pressure. Thus by calculating the rate of entropy generation for each component, the contribution to lost available work due to that component can be determined. The rate of entropy generation for 
each component is readily derived from the general statement of the second law for open systems [4]:

$$
\dot{S}_{g e n}=\frac{d S_{c v}}{d t}-\sum_{i=0}^{n} \frac{\dot{Q}_{i}}{T_{i}}+\sum_{o u t} \dot{m} s-\sum_{\text {in }} \dot{m} s
$$

where $\dot{Q}_{i}$ is the $\mathrm{i}^{\text {th }}$ heat interaction of the corresponding component with the surrounding (positive when heat transfer takes place from surrounding to the control volume) and $T_{i}$ is the temperature of that portion of the control surface through which the $i^{\text {th }}$ heat interaction occurs. In calculating last two terms on the right hand side of Equation (2) one may frequently encounter the case of calculating $\Delta \mathrm{s}$ terms for steam and oil. For steam the corresponding terms are read from standard thermodynamic tables while for oil (both the collector field oil and the new collector oil) the $\Delta$ s terms are determined using their specific heats as a function of temperature. Starting from the well-known first law relation [4] and treating oil as an incompressible liquid the $\Delta \mathrm{s}$ term associated with oil can be written as:

$$
\begin{aligned}
& T d s=d h-v d P \stackrel{d P=0}{\longrightarrow} d s=d h / T \stackrel{d h=C_{p} d T}{\longrightarrow} d s=C_{p} d T / T \\
& \Delta s=\int_{T_{\text {in }}}^{T_{\text {out }}} \frac{C_{p}}{T} d T
\end{aligned}
$$

It should be noted that in the use of equation (4), the temperatures should be considered in an absolute temperature scale (Kelvin in this work). Having the complete set of states for the current configuration and assuming that the states of steam cycle remain unchanged (which seems reasonable) the new intermediate temperatures have been determined by applying energy balance using an available solver code.

\section{Results}

After satisfying energy balance for the whole system in every configuration, the state at each node becomes fixed. Knowing the fixed states, the values of entropy generation and subsequently the values of lost available work can be readily determined. In the following four tables the values of $\dot{W}_{\text {lost }}$ for the main components in each configuration have been presented.

\section{Example calculation 1:}

The lost available work for exchanger E201 in case B for a turbine outlet pressure of $10 \mathrm{kPa}$ : $\dot{m}_{h}=14 \mathrm{~kg} / \mathrm{s}, \dot{m}_{c}=0.7525 \mathrm{~kg} / \mathrm{s}, T_{h, i}=231.6^{\circ} \mathrm{C}, T_{h, o}=221.1^{\circ} \mathrm{C}, T_{c, i}=98.53^{\circ} \mathrm{C}, T_{c, o}=217.9^{\circ} \mathrm{C}$ $P_{c}=22.3$ bara $\Rightarrow s_{c, i}=1.28866 \mathrm{~kJ} / \mathrm{kg} . \mathrm{K}, \mathrm{s}_{c, o}=2.49896 \mathrm{~kJ} / \mathrm{kg} . \mathrm{K} \Rightarrow \Delta \mathrm{s}_{c}=1.2103 \mathrm{~kJ} / \mathrm{kg} . \mathrm{K}$ For hot fluid (Behran Oil): $C_{p}=0.8132+3.706 \times 10^{-3}(T+273) \Rightarrow \Delta s_{h}=-0.05601 \mathrm{~kJ} / \mathrm{kg} . \mathrm{K}$ $\dot{Q}_{c . v .}=0 \Rightarrow \dot{S}_{g e n}=\dot{m}_{h} \Delta s_{h}+\dot{m}_{c} \Delta s_{c}=0.1266 \mathrm{~kW} / \mathrm{K}$ $T_{0}=25^{\circ} \mathrm{C}=298 \mathrm{~K} \Rightarrow W_{\text {lost }}=37.72 \mathrm{~kW}$ 
Table 1. Values of lost available work for cases A \& B with turbine outlet pressure of $10 \mathrm{kPa}$.

\begin{tabular}{|c|c|c|c|c|c|}
\hline \multicolumn{3}{|c|}{ case $\mathrm{A}$} & \multicolumn{3}{|c|}{ case B } \\
\hline $\begin{array}{c}\text { Component } \\
\text { Type }\end{array}$ & $\begin{array}{c}\text { Component } \\
\text { Name }\end{array}$ & $\begin{array}{l}\dot{W}_{\text {lost }} \\
(k W)\end{array}$ & $\begin{array}{l}\dot{W}_{\text {lost }} \\
(k W)\end{array}$ & $\begin{array}{c}\text { Component } \\
\text { Name }\end{array}$ & $\begin{array}{c}\text { Component } \\
\text { Type }\end{array}$ \\
\hline \multirow{5}{*}{ Exchanger } & E201 & 35.30 & 37.72 & E201 & \multirow{5}{*}{ Exchanger } \\
\hline & E202 & 45.02 & 48.44 & E202 & \\
\hline & E203 & 3.14 & 3.67 & E203 & \\
\hline & Е 204 & 5.90 & 3.39 & E 204 & \\
\hline & - & - & 2.82 & E205 & \\
\hline \multirow{2}{*}{ Boiler } & V301 & 143.81 & 237.47 & V301 & \multirow{2}{*}{ Boiler } \\
\hline & V301 SH & 0.69 & 15.53 & V301 SH & \\
\hline Deaerator & D301 & 63.32 & 64.14 & D301 & Deaerator \\
\hline Condenser & E301 & 146.75 & 150.01 & E301 & Condenser \\
\hline \multirow[t]{2}{*}{ Turbine } & N301 & 321.59 & 318.58 & N301 & \multirow[t]{2}{*}{ Turbine } \\
\hline & P301A & 0.42 & 0.46 & P301A & \\
\hline \multirow[t]{3}{*}{ Pump } & P301B & 0.25 & 0.22 & P301B & \multirow[t]{3}{*}{ Pump } \\
\hline & P302 & 0.96 & 0.89 & P302 & \\
\hline & $\mathrm{V}-100$ & 3.30 & 4.43 & V-100 & \\
\hline \multirow[t]{2}{*}{ Tank } & $V-101$ & 0.00 & 0.01 & $\mathrm{~V}-101$ & \multirow[t]{2}{*}{ Tank } \\
\hline & V-102 & 0.08 & 0.16 & V-102 & \\
\hline Mixer & MIX-100 & 0.43 & 0.71 & MIX-100 & Mixer \\
\hline
\end{tabular}

Table 2. Values of lost available work for cases A \& B with turbine outlet pressure of $25 \mathrm{kPa}$.

\begin{tabular}{|c|c|c|c|c|c|}
\hline \multicolumn{3}{|c|}{ case $\mathrm{A}$} & \multicolumn{3}{|c|}{ case B } \\
\hline $\begin{array}{l}\text { Component } \\
\text { Type }\end{array}$ & $\begin{array}{c}\text { Component } \\
\text { Name }\end{array}$ & $\begin{array}{l}\dot{W}_{\text {lost }} \\
(k W)\end{array}$ & $\begin{array}{l}\dot{W}_{\text {lost }} \\
(k W)\end{array}$ & $\begin{array}{l}\text { Component } \\
\text { Name }\end{array}$ & $\begin{array}{l}\text { Component } \\
\text { Type }\end{array}$ \\
\hline \multirow{5}{*}{ Exchanger } & E201 & 34.69 & 39.85 & E201 & \multirow{5}{*}{ Exchanger } \\
\hline & E202 & 44.94 & 48.14 & E202 & \\
\hline & E203 & 2.35 & 1.49 & E203 & \\
\hline & E 204 & 7.12 & 3.93 & E 204 & \\
\hline & - & - & 4.45 & E205 & \\
\hline \multirow{2}{*}{ Boiler } & V301 & 348.17 & 320.46 & V301 & \multirow{2}{*}{ Boiler } \\
\hline & V301 SH & 0.92 & 21.22 & V301 SH & \\
\hline Deaerator & D301 & 43.01 & 43.74 & D301 & Deaerator \\
\hline Condenser & E301 & 311.02 & 310.46 & E301 & Condenser \\
\hline \multirow[t]{2}{*}{ Turbine } & N301 & 300.20 & 300.27 & N301 & Turbine \\
\hline & P301A & 0.41 & 0.43 & P301A & \\
\hline \multirow[t]{3}{*}{ Pump } & P301B & 0.33 & 0.29 & P301B & Pump \\
\hline & P302 & 0.12 & 0.10 & P302 & \\
\hline & V-100 & 3.53 & 3.59 & V-100 & \\
\hline \multirow[t]{2}{*}{ Tank } & V-101 & 0.12 & 0.21 & V-101 & Tank \\
\hline & V-102 & 0.00 & 0.16 & V-102 & \\
\hline Mixer & MIX-100 & 0.53 & 0.00 & MIX-100 & Mixer \\
\hline
\end{tabular}

\section{Example calculation 2:}

The lost available work for condenser E301 in case A for a turbine outlet pressure of $25 \mathrm{kPa}$ : $\dot{m}_{h}=1.1375 \mathrm{~kg} / \mathrm{s}, P_{h, i}=0.25 \mathrm{bara}, T_{h, i}=65.0^{\circ} \mathrm{C}, P_{h, o}=0.2 \mathrm{bara}, T_{h, o}=60.09^{\circ} \mathrm{C}, x_{h, o}=0.967$ 
$\Rightarrow s_{h, i}=7.59958 \mathrm{~kJ} / \mathrm{kg} \cdot \mathrm{K}, h_{h, i}=2540 \mathrm{~kJ} / \mathrm{kg}, s_{h, o}=0.83217 \mathrm{~kJ} / \mathrm{kg} \cdot \mathrm{K}, h_{h, o}=250 \mathrm{~kJ} / \mathrm{kg}$

$\Rightarrow \Delta s_{h}=-6.76741 \mathrm{~kJ} / \mathrm{kg} . \mathrm{K}$

$\dot{Q}_{c . v .}=\dot{m} \Delta h_{h}=-2605 \mathrm{~kW} \Rightarrow \dot{S}_{\text {gen }}=-\frac{-2605}{298}+1.1375(-6.76741)=1.04368 \mathrm{~kW} / \mathrm{K}$

$T_{0}=25^{\circ} \mathrm{C}=298 \mathrm{~K} \Rightarrow W_{\text {lost }}=311.02 \mathrm{~kW}$

In the above calculation, the dryness fraction at the turbine outlet has been determined by considering an isentropic efficiency of $60 \%$ for the turbine which is a reasonable value for a turbine of this capacity.

Table 3. Values of lost available work for cases A \& B with turbine outlet pressure of $100 \mathrm{kPa}$.

\begin{tabular}{|c|c|c|c|c|c|}
\hline \multicolumn{3}{|c|}{ case $A$} & \multicolumn{3}{|c|}{ case B } \\
\hline $\begin{array}{l}\text { Component } \\
\text { Type }\end{array}$ & $\begin{array}{c}\text { Component } \\
\text { Name }\end{array}$ & $\begin{array}{l}\dot{W}_{\text {lost }} \\
(k W)\end{array}$ & $\begin{array}{l}\dot{W}_{\text {lost }} \\
(k W)\end{array}$ & $\begin{array}{c}\text { Component } \\
\text { Name }\end{array}$ & $\begin{array}{c}\text { Component } \\
\text { Type }\end{array}$ \\
\hline \multirow{5}{*}{ Exchanger } & E201 & 35.34 & 37.72 & E201 & \multirow{5}{*}{ Exchanger } \\
\hline & E202 & 44.32 & 48.44 & E202 & \\
\hline & E203 & 1.75 & 3.67 & E203 & \\
\hline & E 204 & 8.33 & 3.39 & E 204 & \\
\hline & - & - & 2.82 & E205 & \\
\hline \multirow{2}{*}{ Boiler } & V301 & 555.16 & 517.80 & V301 & \multirow{2}{*}{ Boiler } \\
\hline & V301 SH & 13.49 & 33.84 & V301 SH & \\
\hline Deaerator & D301 & 4.23 & 3.84 & D301 & Deaerator \\
\hline Condenser & E301 & 689.24 & 684.55 & E301 & Condenser \\
\hline \multirow[t]{2}{*}{ Turbine } & N301 & 273.29 & 273.37 & N301 & \multirow[t]{2}{*}{ Turbine } \\
\hline & P301A & 0.41 & 0.46 & P301A & \\
\hline \multirow[t]{3}{*}{ Pump } & P301B & 0.53 & 0.49 & P301B & \multirow[t]{3}{*}{ Pump } \\
\hline & P302 & 0.00 & 0.00 & P302 & \\
\hline & V-100 & 4.43 & 4.62 & V-100 & \\
\hline \multirow[t]{2}{*}{ Tank } & V-101 & 0.16 & 0.01 & V-101 & \multirow[t]{2}{*}{ Tank } \\
\hline & V-102 & 0.00 & 0.00 & V-102 & \\
\hline Mixer & MIX-100 & 0.17 & 1.47 & MIX-100 & Mixer \\
\hline
\end{tabular}

Table 4. Values of lost available work for Night case with turbine outlet pressures of 10,25 and 100 $k P a$.

\begin{tabular}{ccccc}
\hline \multirow{2}{*}{$\begin{array}{c}\text { Component } \\
\text { Type }\end{array}$} & Component & \multicolumn{3}{c}{$\dot{W}_{\text {lost }}(\mathrm{kW})$} \\
\cline { 3 - 5 } & Name & $10 \mathrm{kPa}$ & $25 \mathrm{kPa}$ & $100 \mathrm{kPa}$ \\
\hline \multirow{2}{*}{ Boiler } & V301 & 707.79 & 780.60 & 985.28 \\
& V301 SH & 46.90 & 51.68 & 65.26 \\
Deaerator & $\mathrm{D} 301$ & 73.33 & 43.76 & 3.96 \\
Condenser & $\mathrm{E} 301$ & 151.74 & 310.46 & 689.24 \\
Turbine & $\mathrm{N} 301$ & 318.96 & 300.27 & 273.29 \\
Pump & $\mathrm{P} 301 \mathrm{~B}$ & 0.65 & 0.71 & 0.90 \\
& $\mathrm{P} 302$ & 0.09 & 0.10 & 0.00 \\
Tank & $\mathrm{V}-100$ & 3.27 & 3.59 & 4.54 \\
& $\mathrm{~V}-102$ & 0.17 & 0.00 & 0.00 \\
\hline
\end{tabular}

It is worth mentioning that, generally in solar thermal power plants the major fraction of total exergy loss takes places in the collector field (mainly due to the ultra high temperature of the 
sun)[5]. However, in the present work, the operating conditions of the collector field are the same in all configurations. Thus the exergy loss due to the collector field is not reported for comparison. It should also be noted that the night cycle is essentially either cases A or B in which no collector is at service and boilers are the only suppliers of thermal energy to the system. A quick study of tables 1-4 reveals the fact that, generally by decreasing the turbine outlet pressure, the value of lost work decreases in the corresponding devices. Moreover reducing the turbine outlet pressure increases the amount of power which can be extracted from the turbine. But, as expected, these advantages have their own counterparts; the need for creating vacuum condition for condenser, the need to change the condenser type from aircooled to water-cooled, etc. Another implication is that in each configuration the dominant sources of lost work are boilers, condensers and turbines and that the contribution made by pumps, mixers and tanks are negligible.

From another point of view, comparing the values of lost available work for same devices, one may conclude that, in the same operating conditions, case A is thermodynamically superior to case B.

\section{Conclusions}

- The concept of lost available work has been utilized to select the best choice of integration of a hybrid solar power plant.

- Regarding various cases, it is found that case A is thermodynamically the preferred case for integration.

- Case A has the advantage of requiring one less extra heat exchanger to be integrated into the current configuration.

- For optimum integration, one must also take into account the economic aspect of each case. In other words, a thorough thermo-economic analysis might be proper to further assess these two proposed cases.

- Moreover one should also consider water consumption rate for each case. Water is rarely available especially for regions where solar energy is considerable and such limitation might sacrifice higher efficiencies or lower available lost work for the final decision.

\section{References}

[1] R. Shinnar, F. Citro, Solar thermal energy: The forgotten energy source, Journal of Technology in Society 29, 2007, pp.261-270

[2] K. Azizian, M. Yaghoubi, R. Heasmi, S. Mirhadi, Shiraz pilot solar thermal power plant design, construction, installation and commissioning procedure, Proceedings of 7 th International Conference on Heat transfer, Fluid mechanics and Thermodynamics, 2010

[3] A. Baghernejad, M. Yaghoubi, Multi-objective exergoeconomic optimization of an integrated solar combined cycle system using evolutionary algorithms, International Journal of Energy Research, 2010

[4] A. Bejan, Advanced Engineering Thermodynamics, Wiley, $2^{\text {nd }}$ Edition, 1997

[5] M.K. Gupta, S.C. Kaushik, Exergy analysis and investigation for various feed water heaters of direct steam generation solar thermal power plant, Journal of Renewable Energy 35, 2010, pp.1228-1235 